\title{
Photophysical and Electrochemical Properties of meso-Substituted Thien-2-yl Zn(II) Porphyrins
}

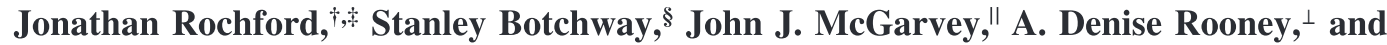 \\ Mary T. Pryce*,‡
}

School of Chemical Sciences, SRC for Solar Energy Conversion, Dublin City University, Dublin 9, Ireland, Central Laser Facility, Rutherford Appleton Laboratory, Chilton, Didcot, Oxfordshire OX11 OQX, United Kingdom, School of Chemistry, The Queen's University of Belfast, Belfast BT9 5AG, Northern Ireland, United Kingdom, and Department of Chemistry, National University of Ireland Maynooth, Co. Kildare, Ireland

Received: July 2, 2008; Revised Manuscript Received: September 5, 2008

\begin{abstract}
The influence of the thiophene ring on the ground and excited state properties of the porphyrin ring is investigated, when substituted at the meso-position. A series of mono-, di-, tri-, and tetra-meso-thien-2-yl porphyrins are studied and discussed with respect to the reference compounds zinc(II)-5,10,15,20-tetra(thien2 '-yl)porphyrin (1a) and zinc(II)-5,10,15,20-tetraphenylporphyrin (ZnTPP). The extended conjugated system zinc(II)-5-(5'-(5"-ethynyl-2"-thiophenecarboxaldehyde)thien-2'-yl)-10,15,20-triphenylporphyrin (4d) is also studied and shows enhanced charge transfer character due to the presence of the terminal aldehyde accepting group. A detailed analysis of ground and excited state UV-vis absorption, steady-state and time-resolved fluorescence, laser flash photolysis, and electrochemical data all point toward substantial electronic communication between the central $\mathrm{Zn}$ (II) porphyrin ring and the meso-thien-2-yl substituents, which is evident from excited state charge transfer character.
\end{abstract}

\section{Introduction}

Porphyrin-based systems are widely studied because of their catalytic, ${ }^{1}$ therapeutic, ${ }^{2}$ and potential optoelectronic applications. $^{3}$ The diverse range of applications for porphyrins stems from their stable and rigid structure, which possesses unique photophysical and electrochemical properties. The construction of porphyrins and their metal complexes, which mimic hemecontaining proteins as well as the photosynthetic reaction centers, has been the foundation of many studies across a broad spectrum of scientific disciplines. The reversibility of the redox chemistry shown by porphyrins, i.e. the stability of both their mono- and dicationic species, makes them particularly attractive for photoionization and photoconductive processes. Such studies are well documented in the mimicking of the photosynthetic reaction center by photoinduced electron transfer with use of porphyrin-based electron reservoirs. ${ }^{4}$ Porphyrins can be designed and tailored for such applications by varying the metal center and also by controlling the substituents attached at the periphery of the macrocycle.

In the study presented here electronic communication between the zinc(II) porphyrin macrocycle, having the traditional $\mathrm{N}_{4}$ core, and its peripheral substituents is investigated via ground and excited state photophysical studies as well as electrochemical methods. The influence of successive thien-2-yl groups on the porphyrin ring is investigated in a series of mono-, di-, tri-, and tetra-meso-thien-2-yl-substituted $\mathrm{Zn}$ (II) porphyrins where it is shown that the photophysical and redox properties can be

* Corresponding author. Phone: +353 1 7008005. E-mail: mary.pryce@ dcu.ie.

$\dagger$ Current address: Chemistry Department, Brookhaven National Laboratory, Upton, NY 11973-5000.

$\$$ Dublin City University.

$\S$ Rutherford Appleton Laboratory.

"The Queen's University of Belfast.

${ }^{\perp}$ National University of Ireland Maynooth. tuned accordingly by the number of thien-2-yl substituents present on the porphyrin ring. Previous studies on mesothienylporphyrins have focused on a wide variety of applications such as the mimicking of proteins and enzymes, ${ }^{5}$ conducting polymers, ${ }^{6}$ optoelectronic materials,${ }^{7}$ magnetic materials, ${ }^{8}$ and energy/electron transfer in artificial photosynthetic devices. ${ }^{9}$ In contrast to the standard ZnTPP system, optical excitation of the meso-thien-2-yl-substituted porphyrins here studied results in excited state charge transfer from the porphyrin chromophore onto the peripheral thien-2-yl substituents. This is evident in a broad low-energy absorption observed in the transient difference absorbance UV-vis spectra, the intensity of which is dependent both on the number of thienyl substituents present on the porphyrin ring system (Figure 5 discussed below) and also the nature of the substituent on the thien-2-yl ring itself, e.g., ZnTMSEtThTPP (4b) vs Zn(AldThEtTh)TPP (4d). The excited state charge transfer character observed for these systems substantiates their recent popularity as electron donors, over ZnTPP-based systems, in devices which utilize photoinduced charge-separation akin to photosystem II in the natural photosynthetic system. There are just a small number of reports which directly address the influence of the thiophene ring on the electronic properties of the porphyrin macrocycle. ${ }^{10} \mathrm{Few}$ of these studies involve thienylporphyrin systems with the traditional $\mathrm{N}_{4}$-core. ${ }^{10 a, c, e, f}$ Bhyrappa and Bhavana reported a decrease in the HOMO-LUMO energy gap for meso-tetra(thien-2-yl)porphyrin with respect to meso-tetra(thien-3-yl)porphyrin and tetraphenylporphyrin as the free base, $\mathrm{Zn}^{\mathrm{II}}$ and $\mathrm{Cu}^{\mathrm{II}}$ derivatives. ${ }^{10 a}$ However, the changes observed in the UV-vis spectra as well as in the redox potentials of the compounds studied were attributed to inductive effects of the unsubstituted thienyl groups at the porphyrin ring. Sun et al. reported a 15 $\mathrm{nm}$ red shift of the Soret band for tetra-5,10,15,20-(5'-methylthien-2'-yl)porphyrin free base with respect to the tetraphenyl analogue and positive solvatochromic behavior attributed to 
extended conjugation; however, decreased quantum yields and fluorescence lifetimes were attributed again to an inductive effect. ${ }^{10 \mathrm{c}}$ A later study by Bhyrappa et al. showed how the porphyrin core in $\mathrm{Zn}$ (II)-tetra-5,10,15,20-(thien-2'-yl)porphyrin adapts a saddle conformation in the solid state; however, the reduced fluorescence quantum yield was not explained. ${ }^{10 \mathrm{e}}$ Perhaps the most convincing investigation to date inferring electronic communication between the porphyrin macrocycle and the meso-thienyl substituents is that by Brückner et al. where a combination of UV-vis absorption, steady-state fluorescence, X-ray crystallography, and density functional theory (DFT) analysis led the authors to conclude that a reduced dihedral angle of the thienyl group at the porphyrin ring results in resonance interaction between the two $\pi$-systems. ${ }^{10 f}$ To date, however, there lacks a detailed investigation of the influence of the thienyl ring on the excited state properties of the porphyrin ring system.

\section{Experimental Section}

The synthesis of all porphyrins studied here is described in detail in the Supporting Information. All UV-vis spectra were measured in spectroscopic grade toluene (Aldrich) at room temperature on a Hewlett-Packard 8452A-photodiode array spectrometer, using a $1 \mathrm{~cm}$ quartz cell. Steady state fluorescence measurements were carried out on a Perkin-Elmer LS50 luminescence spectrometer at room temperature. Fluorescence quantum yields for the samples $\left(\Phi_{\mathrm{fl}}\right)$ were calculated in toluene solutions deareated by freeze - pump - thaw technique at $\lambda_{\text {exc }}=$ $550 \mathrm{~nm}$, using the optically dilute technique with $\mathrm{Zn}$ (II)5,10,15,20-tetraphenylporphyrin (ZnTPP) as the actinometer $\left(\Phi_{\text {ref }}=0.033\right),{ }^{11}$ according to eq 1 .

$$
\Phi_{\mathrm{fl}}=\left(A_{\mathrm{ref}} / A_{\mathrm{s}}\right)\left(I_{\mathrm{s}} / I_{\mathrm{ref}}\right)\left(\eta_{\mathrm{s}} / \eta_{\mathrm{ref}}\right)^{2} \Phi_{\mathrm{ref}}
$$

The subscript "s" refers to the sample and the subscript "ref" to the reference sample (in this case ZnTPP), $A$ is the absorbance at the excitation wavelength, $I$ is the integrated emission area, and $\eta$ is the solvent refractive index. Excitation and emission slits were both set at $10 \mathrm{~nm}$. Transient absorption measurements following laser flash photolysis at 355 and $532 \mathrm{~nm}$ were carried out in toluene under $1 \mathrm{~atm}$ of argon at room temperature with a typical sample absorbance of $0.05( \pm 0.01)$ AU corresponding to concentrations in the order of $<1 \times 10^{-6} \mathrm{M}$. All transient species observed were independent of excitation wavelength and formed within the lifetime of the laser pulse (ca. $10 \mathrm{~ns}$ ). The transient absorption difference spectra are attributed to the lowest ${ }^{3}\left(\pi-\pi^{*}\right)$ porphyrin triplet excited state. Second-order kinetics have previously been used to determine the triplet decay of similar porphyrin complexes due to competition between firstorder decay and bimolecular triplet-triplet annihilation. ${ }^{12}$ All of the transient signals recorded in this study fit well with monoexponential kinetics indicating unimolecular decay at these low concentrations. Samples for time-resolved single photon counting (TR-SPC) studies were carried out under similar conditions as the steady state measurements. The experimental apparatus has been described previously. ${ }^{13}$ Fluorescence lifetimes, $\tau_{\mathrm{fl}}$, were measured at the emission maximum of the porphyrin under investigation following excitation at $435 \mathrm{~nm}$. The radiative rate constant $\left(k_{\mathrm{r}}\right)$ and nonradiative rate constant $\left(k_{\mathrm{n}}\right)$ were both calculated from $\tau_{\mathrm{fl}}$ and $\Phi_{\mathrm{fl}}$ by using eqs $2-5$.

$$
\begin{gathered}
\tau_{\mathrm{fl}}=1 /\left(k_{\mathrm{r}}+k_{\mathrm{nr}}\right) \\
\Phi_{\mathrm{fl}}=k_{\mathrm{r}} /\left(k_{\mathrm{r}}+k_{\mathrm{nr}}\right) \\
k_{\mathrm{r}}=\Phi_{\mathrm{fl}} / \tau_{\mathrm{fl}}
\end{gathered}
$$

$$
k_{\mathrm{nr}}=\left(1-\Phi_{\mathrm{fl}}\right) / \tau_{\mathrm{fl}}
$$

Cyclic voltammetry was performed with a $\mathrm{CH}$ Instruments potentiostat under nitrogen at room temperature at a scan rate of $100 \mathrm{mV} \mathrm{s}^{-1}$ with a conventional three-electrode configuration consisting of a glassy carbon working electrode $(3 \mathrm{~mm}$ diameter), a platinum wire auxiliary electrode, and a $\mathrm{Ag} / \mathrm{AgCl}$ reference electrode (calibrated externally versus the ferrocene/ ferricenium $\left(\mathrm{Fc}^{+} / \mathrm{Fc}\right)$ redox couple). The supporting electrolyte was $0.1 \mathrm{M} \mathrm{Bu}_{4} \mathrm{NBF}_{4}$ (Fluka Chemicals) in spectrophotometric grade dichloromethane (Aldrich). The half-wave potential, $E_{1 /}$ 2, was determined as $\left(E_{\mathrm{pa}}+E_{\mathrm{pc}}\right) / 2$, where $E_{\mathrm{pa}}$ and $E_{\mathrm{pc}}$ are the anodic and cathodic peak potentials, respectively (it is assumed that $E_{1 / 2} \cong E^{0 \prime}$ for all measurements). Where $E_{1 / 2}$ could not be calculated due to irreversible oxidation or reduction processes $E_{\mathrm{pa}}$ and $E_{\mathrm{pc}}$ are quoted, respectively. $E_{0-0}$ was calculated from the intersection of the porphyrin absorption spectrum with the fluorescence emission spectrum in toluene at normalized absorption and emission intensity.

\section{Results and Discussion}

Synthesis and ${ }^{\mathbf{1}} \mathbf{H}$ NMR spectra. The synthesis of all mesothien-2-ylporphyrins studied here is described in the Supporting Information. Briefly, the meso-tetrathien-2-ylporphyrin systems were synthesized by using standard conditions involving the condensation of the 5-substituted 2-thiophenecarboxaldehyde with pyrrole. The mono-, di-, and trithien-2-yl systems were prepared by a mixed condensation reaction of the 5-bromo-2thiophenecarboxaldehyde and benzaldehyde with pyrrole, ${ }^{14,15}$ followed by metalation and Sonogashira coupling of the trimethylsilylethynyl moiety. To prepare the ZnT(TMSEtTh)P (2c) system a Sonogashira reaction was again employed. This coupling reaction could be carried out at the thiophene ring before or after porphyrin formation; however, yields were slightly higher with the latter methodology. The cis and trans isomers of $\mathrm{ZnD}$ (TMSEtTh)DPP (6b) proved inseparable and were thus used as a mixture throughout this study. ${ }^{16} \mathrm{Zn}$ (TMSEtTh)TPP (4c) was further functionalized, under Sonogashira conditions, at the terminal ethynyl moiety with 5-bromo-2thiophenecarboxaldehyde giving the $\pi$-extended porphyrin $\mathrm{Zn}$ (AldThEtTh)TPP (4d) in high yield. Each of the $\mathrm{A}_{4}$-type meso-substituted porphyrins ZnTPP, ZnTThP (2a), ZnTBrThP (2b), ZnT(TMSEtTh)P (2c), and ZnTEtThP (2d) are of $S_{4}$ symmetry and possess a $C_{4}$ rotational axis through the metal center perpendicular to the plane of the porphyrin ring (Figure $\mathrm{S} 1$, Supporting Information). ${ }^{17}$ Each of the $\beta$-pyrrolic protons are therefore in an identical magnetic environment as is evident in the ${ }^{1} \mathrm{H}$ NMR spectra by their appearance as a sharp singlet (Figure S2, Supporting Information). This singlet occurs at 8.87 ppm for ZnTPP; however, it is shifted slightly downfield for the meso-tetrathien-2-yl porphyrins (9.07 ppm for $\mathbf{2 a}, 9.12 \mathrm{ppm}$ for $\mathbf{2 b}, 9.08 \mathrm{ppm}$ for $\mathbf{2 c}$, and $9.11 \mathrm{ppm}$ for $\mathbf{2 d}$ ). This deshielding effect of the $\beta$-pyrrolic protons observed for the meso-tetrathien2 -yl porphyrins is in accordance with previous literature reports and is attributed to an increase in the ring current of the porphyrin ring caused by delocalization onto the peripheral thien-2-yl units. ${ }^{10,18}$ The thien-2-yl proton signals are typical of a 2-substituted thiophene system for ZnTThP (2a) and of a 2,5-disubstituted thiophene system for ZnTBrThP (2b), ZnT(TMSEtTh)P (2c), and ZnTEtThP (2d); however, they are shifted slightly downfield due to the close proximity of the porphyrin ring current. ${ }^{18}$ On lowering the symmetry of the ring by introducing nonequivalent groups at the meso-position of the porphyrin ring the ${ }^{1} \mathrm{H}$ NMR spectra become more complex (see the Supporting Information). 

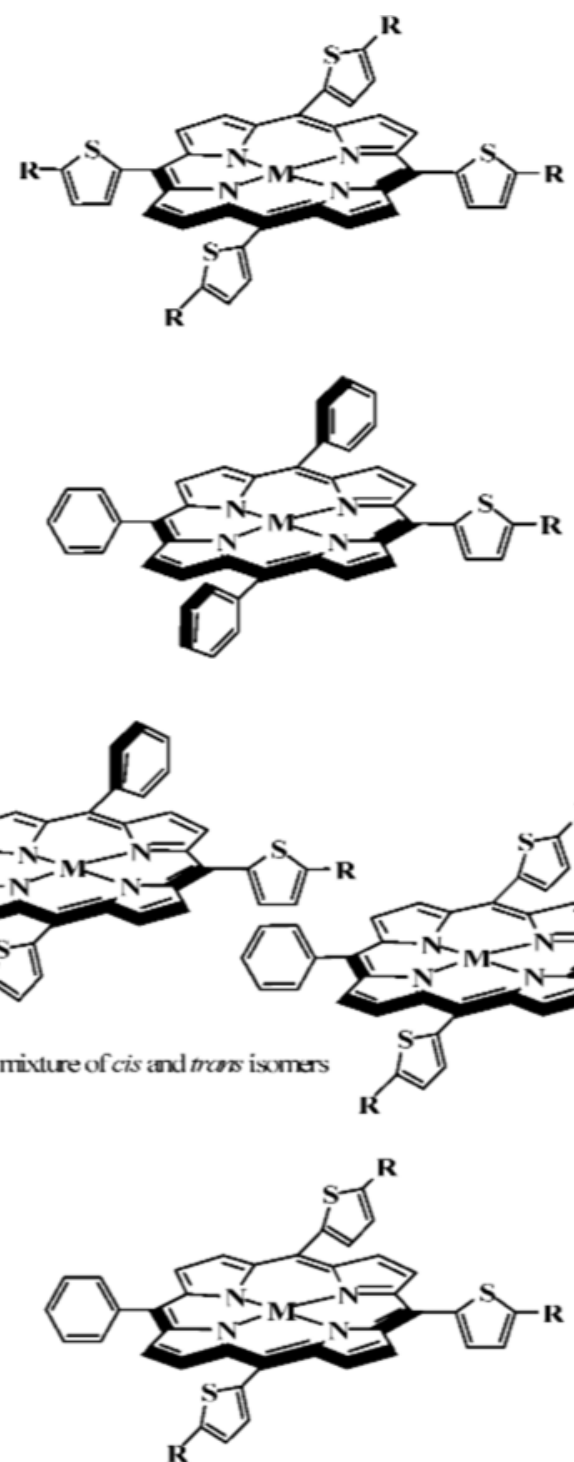

$\underline{\mathbf{R}}$

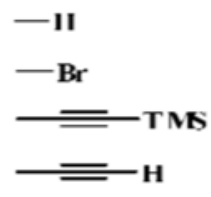

$\underline{\mathbf{R}}$

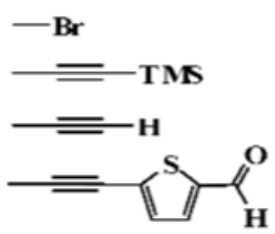

$\underline{\mathbf{R}}$

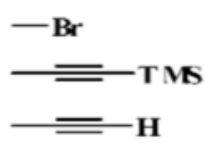

$\underline{\mathbf{R}}$

$\underline{M=2 H}$

a

,

b

c

d

$\underline{M=2 H}$

3

a

b

$-$

$-$

$\underline{M=2 H}$

5

a

b

$-$

$\underline{M=2 H}$

7

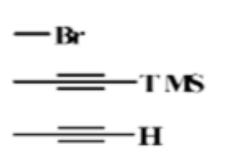

$\underline{M=\ln (10)}$

2

a - Znil'hP

b - 7nTrarThP

c - ZnT(TMSETh)P

d - Jillithl'

\section{M=Zn(II)}

a - $/$ n(Brith)TIP

b - Zn(IMSEXIh)IPP

c - IntrihilP

d - Zn(AldThETh)TPP

$M=7 n(I)$

6

a - ZnD(BrTh)TPP

b - ZnD(TMSERTh)DPP

c - ZnD(ErTh)IPP

Figure 1. Structures of the meso-Zn(II) thien-2-ylporphyrins prepared in this study. Photophysical and electrochemical analysis was carried out on the $\mathrm{Zn}$ (II) derivatives of all meso-tetrathien-2-yl porphyrins and each of the mono-, di-, and tri(trimethylsilylethynylthien-2-yl) and -(ethynylthien2-yl) porphyrin systems.

TABLE 1: Photophysical Data of ZnTPP and meso-Thien-2-ylporphyrins Recorded in Toluene

\begin{tabular}{|c|c|c|c|c|c|c|c|c|c|c|}
\hline \multirow[b]{2}{*}{ porphyrin } & \multicolumn{4}{|c|}{ UV-vis absorption } & \multirow[b]{2}{*}{$\begin{array}{c}\text { fluorescence } \mathrm{Q}(0,0) * \\
\mathrm{Q}(0,1)^{*} \lambda_{\max } \\
\mathrm{nm}\left(\Phi_{\mathrm{fl}}\right)\end{array}$} & \multirow[b]{2}{*}{$\begin{array}{l}\text { Stokes shift, } \\
\times 10^{5} \mathrm{~cm}^{-1}\end{array}$} & \multirow[b]{2}{*}{$\begin{array}{l}\tau_{\mathrm{fl}}, \\
\mathrm{ns}\end{array}$} & \multirow[b]{2}{*}{$\begin{array}{l}{ }^{3} \tau, \\
\mu \mathrm{s}\end{array}$} & \multirow[b]{2}{*}{$\begin{array}{c}k_{\mathrm{fl}} \\
\times 10^{7} \\
\mathrm{~s}^{-1}\end{array}$} & \multirow[b]{2}{*}{$\begin{array}{l}k_{\mathrm{nr}}, \\
\times 10^{8} \\
\mathrm{~s}^{-1}\end{array}$} \\
\hline & 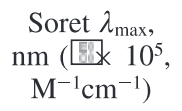 & $\begin{array}{l}\text { fwhm } \\
\left(\mathrm{cm}^{-1}\right)\end{array}$ & $\begin{array}{c}\mathrm{Q}(0,1) \lambda_{\max } \\
\mathrm{nm}\left(\mathbb{W} 10^{3}\right. \\
\left.\mathrm{M}^{-1} \mathrm{~cm}^{-1}\right)\end{array}$ & $\begin{array}{c}\mathrm{Q}(0,0) \lambda_{\max } \\
\mathrm{nm}\left(\left[\mathrm{Dx} 10^{3}\right.\right. \\
\left.\mathrm{M}^{-1} \mathrm{~cm}^{-1}\right)\end{array}$ & & & & & & \\
\hline ZnTPP & $422(2.55)$ & 673 & $548(9.72)$ & $588(1.90)$ & $596,647(0.033)$ & 12.50 & 1.98 & 24 & 1.69 & 4.88 \\
\hline ZnTThP (2a) & $430(2.84)$ & 811 & $556(9.48)$ & $600(1.97)$ & $617,657(0.010)$ & 5.88 & 1.36 & 20 & 0.74 & 7.28 \\
\hline ZnTBrThP (2b) & $434(2.82)$ & 902 & $558(8.57)$ & $600(2.20)$ & $636(0.006)$ & 2.78 & 0.52 & 7 & 1.15 & 19.12 \\
\hline ZnTEtThP (2d) & $436(2.42)$ & 1052 & $560(10.32)$ & $600(2.64)$ & $639,650(0.014)$ & 2.56 & 0.74 & 13 & 1.84 & 13.32 \\
\hline Zn(TMSEtTh)TPP (4b) & $426(2.18)$ & 771 & $552(9.62)$ & $594(2.01)$ & $607,651(0.046)$ & 7.69 & 1.94 & 16 & 2.37 & 4.92 \\
\hline $\mathrm{ZnD}$ (TMSEtTh)DPP (6b) & $430(2.37)$ & 865 & $554(9.64)$ & $598(2.78)$ & $615,647(0.042)$ & 5.88 & 1.48 & 11 & 2.84 & 6.47 \\
\hline ZnT(TMSEtTh)PP (8b) & $434(2.23)$ & 1009 & $556(8.92)$ & $600(2.94)$ & $622,643(0.028)$ & 4.55 & 1.07 & 10 & 2.62 & 9.08 \\
\hline Zn(ThEtThAld)TPP (8d) & $428(2.60)$ & 928 & $552(9.81)$ & $594(1.87)$ & $614,644(0.043)$ & 5.00 & 1.92 & 6 & 2.24 & 4.98 \\
\hline
\end{tabular}

UV-Vis Absorption. There have been mixed reports in the literature of whether there exists electronic communication between the porphyrin ring and thienyl substituents via the mesoposition of the macrocycle. ${ }^{10}$ The systems investigated in this study (Figure 1) suggest that direct attachment of the aromatic thiophene ring at the meso-position of the porphyrin ring does lead to electronic interaction between the two $\pi$-systems, which can be enhanced through appropriate substitution. In support of this, it has been found that by varying the substituent on the 5-position of the thiophene ring a red shift can be induced in the Soret absorption of the porphyrin ring. The UV-vis spectra are compared for the tetrasubsitiuted thiophenes $(\mathbf{2} \mathbf{a}-\mathbf{d})$, and also for the porphyrins where the number of substituents on the macrocycle has been varied, for instance the mono-, di-, and trithien-2-yl porphyrins $(\mathbf{4 a}-\mathbf{d}, \mathbf{6 b}, \mathbf{6 c}, \mathbf{8 b}, \mathbf{8 c})$.

Tetrathien-2-yl Systems. The Soret band is red-shifted by $8 \mathrm{~nm}$ for ZnTThP (2a), $12 \mathrm{~nm}$ for ZnTBrThP (2b), $16 \mathrm{~nm}$ for ZnT(TMSEtTh)P (2c), and $14 \mathrm{~nm}$ for ZnTEtThP (2d) with 
(i)

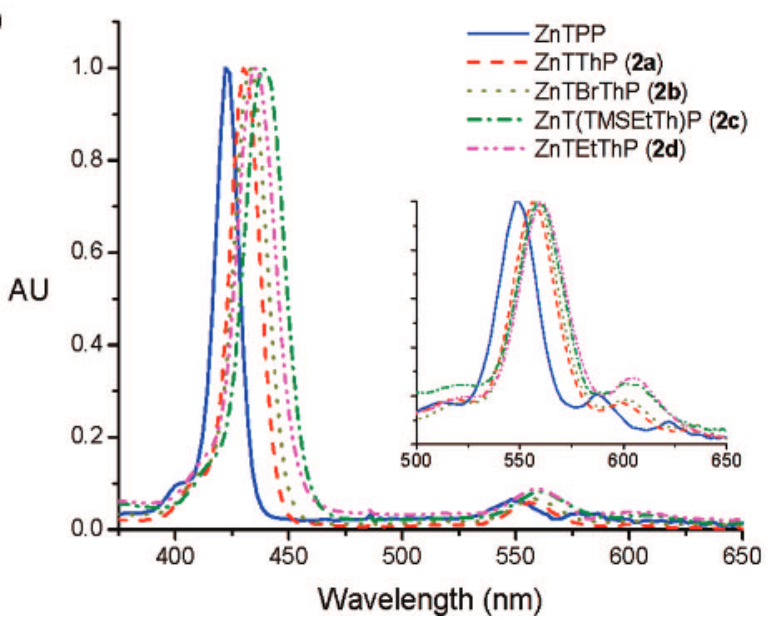

(ii)

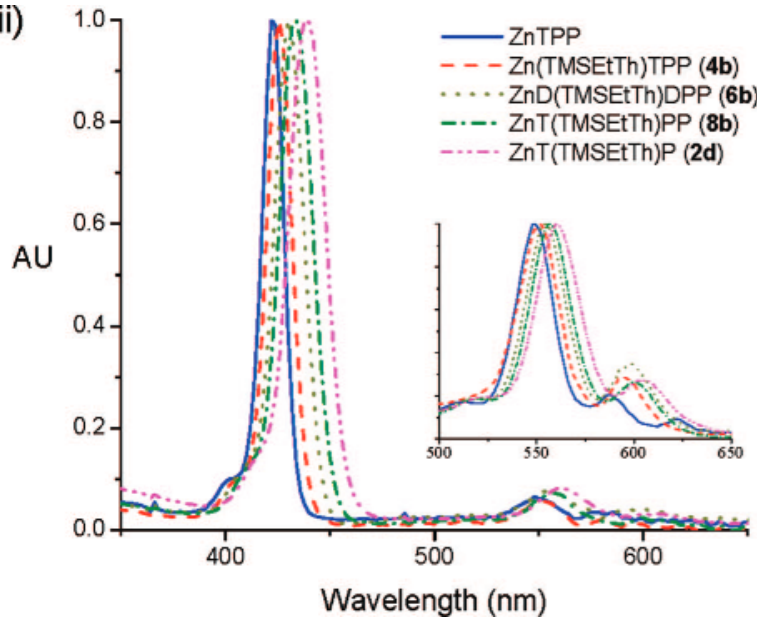

Figure 2. UV-vis absorption spectra of (i) ZnTPP, ZnTThP (2a), ZnTBrThP (2b), ZnTEtThP (2c), and ZnT(TMSEtTh)P and (ii) (2d) ZnTPP, ZnTMSEtThTPP (4b), ZnD(TMSEtTh)DPP (6b), ZnT(TMSEtTh)PP (8b), and ZnT(TMSEtTh)P (2d). All spectra were recorded in toluene at room temperature and have been normalized at their absorption maxima.
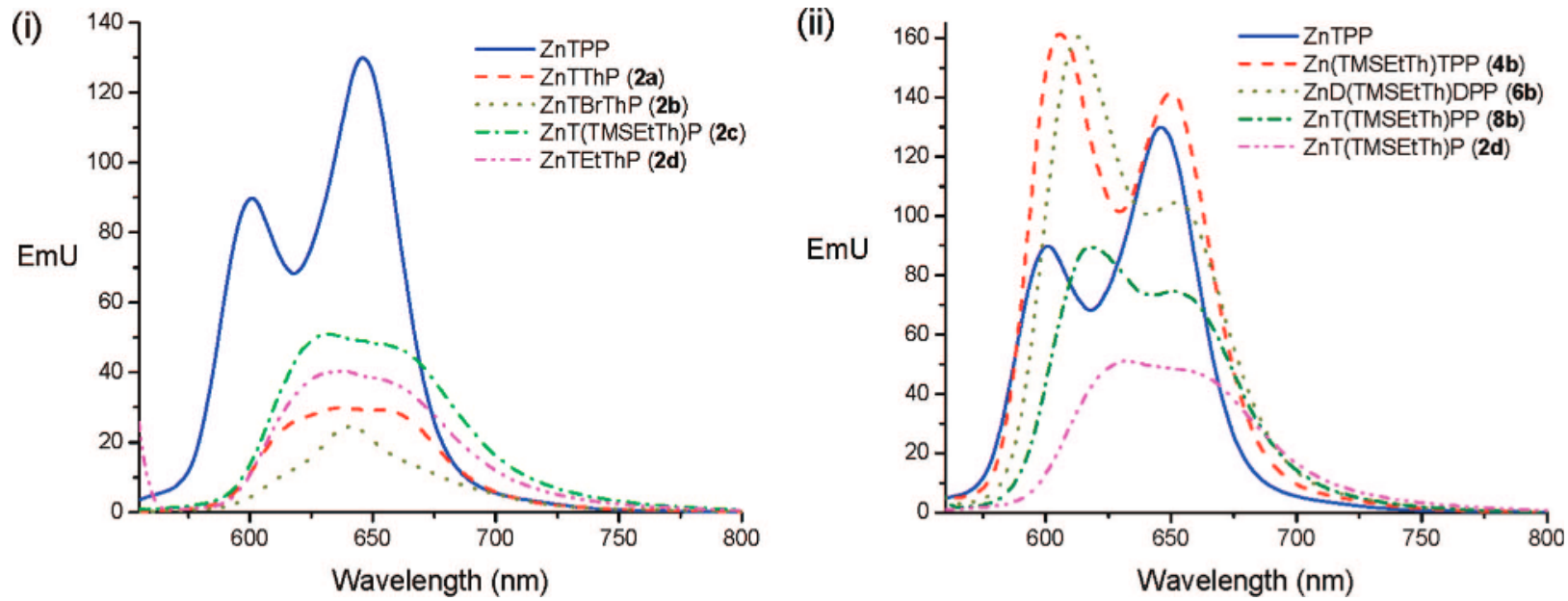

Figure 3. Fluorescence emission spectra of (i) ZnTPP, ZnTThP (2a), ZnTBrThP (2b), ZnT(TMSEtTh)P (2c), and ZnTEtThP (2d) and (ii) ZnTPP $\mathrm{Zn}(\mathrm{TMSEtTh}) \mathrm{TPP}(\mathbf{4 b}), \mathrm{ZnD}$ (TMSEtTh)DPP (6b), ZnT(TMSEtTh)PP (8b), and ZnT(TMSEtTh)P (2d). All spectra were recorded in toluene at room temperature $\left(\lambda_{\mathrm{exc}}=550 \mathrm{~nm}\right.$, abs. $=0.2$ at $\left.550 \mathrm{~nm}\right)$

respect to ZnTPP (Table 1). Such a strong shift would not be anticipated on the basis of an inductive effect of the thien-2-yl substituents alone. ${ }^{19}$ Also, as the Soret band is shifted to lower energy the fwhm increases, which suggests increased electronic and vibronic coupling between the $\pi$-systems of the porphyrin and thien-2-yl rings. ${ }^{20}$ Similar changes are observed for the Q bands. A slight increase in the relative intensity of the $\mathrm{Q}(0,0)$ band occurs as the electronic communication between the porphyrin and thien-2-yl rings is increased. The ratio of the intensity of $\mathrm{Q}(0,0) / \mathrm{Q}(0,1)$ bands increases in the order ZnTThP (2a) $<$ ZnTBrThP (2b) $<$ ZnTEtThP (2d) $<$ ZnT(TMSEtTh)P (2c).

Mono-, Di-, Tri-, and Tetrathien-2-yl Systems. By taking ZnTPP as a template and varying the number of 5-trimethylsilylethynylthien-2-yl substituents at the meso-position of the porphyrin ring a red shift is induced in the Soret absorption (Table 1). An overlay of UV-vis spectra for ZnTPP and the various meso-(5-trimethylsilylethynylthien-2-yl)porphyrins recorded in toluene is shown in Figure 2. The Soret band is shifted by $4 \mathrm{~nm}$ for every 5-trimethylsilylethynylthien-2-yl group resulting in a total shift of $16 \mathrm{~nm}$ for $\mathrm{ZnT}$ (TMSEtTh)P (2c) with respect to $\mathrm{ZnTPP}$ (Table 1). There is also a corresponding increase in the fwhm of the Soret band associated with increasing 5-trimethylsilylethynylthien-2-yl substitution (Table
1). Analogous behavior is observed in the Q-band region and the relative intensity of the $\mathrm{Q}(0,0)$ band to the Soret band increases also (see Table 1 for $\lambda_{\max }$, fwhm and Wata).

These results are comparable with those of Harriman and Davila, and Fonda et al. where on increasing the electronic communication between the central porphyrin ring and the mesosubstituents a red shift and band broadening is observed with a concomitant "intensity exchange" of the $S_{2}$ and $S_{1}$ electronic states, i.e., the $S_{2}$ state loses oscillator strength to the $S_{1}$ state as mixing of these states increases. ${ }^{20}$ According to Gouterman's four orbital model, the intensity of the $\mathrm{Q}(0,0)$ transition is dependent on the energy difference between the porphyrin $a_{1 u}$ $\rightarrow \mathrm{e}_{\mathrm{g}}$ and $\mathrm{a}_{2 \mathrm{u}} \rightarrow \mathrm{e}_{\mathrm{g}}$ transitions and thus the relative energies of the $\mathrm{a}_{1 \mathrm{u}}$ and $\mathrm{a}_{2 \mathrm{u}}$ orbitals. ${ }^{21}$ The thienyl ring, and in particular the 5-trimethylethynylthien-2-yl substituent, is thus having a substantial impact on the energies of the porphyrin $a_{1 u}$ and $a_{2 u}$ orbitals. This trend in results infers to an increased mixing of the $S_{1}$ and $S_{2}$ states of the porphyrin on increasing thien-2-yl substitution and compares well with a previous study by Ravikanth and co-workers who have shown that increasing thienyl and furyl substituents do have an influence on the electronic structure of some nontraditional core modified porphyrin systems. ${ }^{10 \mathrm{~d}, 22}$ It is noteworthy that ZnT(TMSEtTh)P (2c) displays the highest degree of so-called $S_{2}$ to $S_{1}$ "intensity 


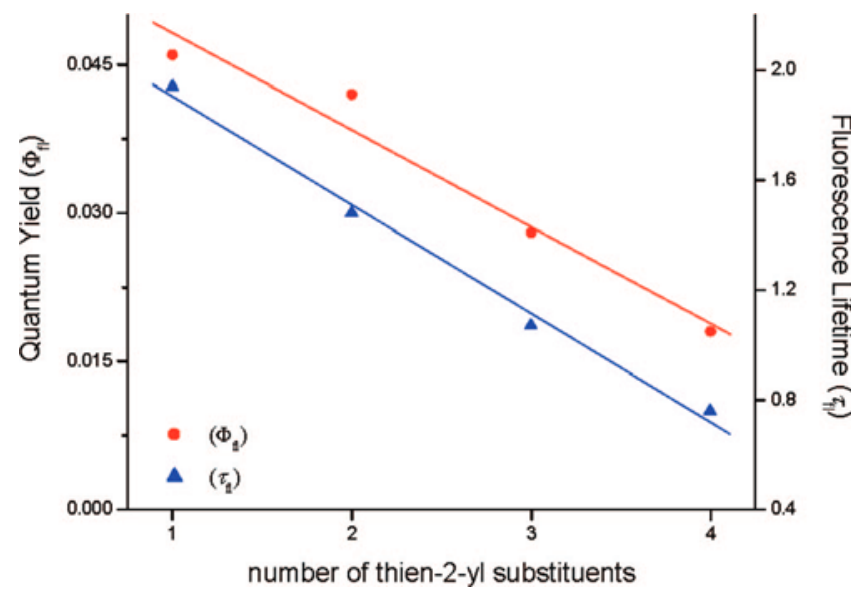

Figure 4. Plots of "quantum yield $\left(\Phi_{\mathrm{fl}}\right)$ " and "fluorescence lifetime $\left(\tau_{\mathrm{fl}}\right)$ " vs "number of thien-2-yl substituents" for porphyrins ZnTMSEtThTPP (4b), ZnD(TMSEtTh)DPP (6b), ZnT(TMSEtTh)PP (8b), and ZnT(TMSEtTh)P (2d). ${ }^{23}$

exchange" of all the 5-trimethylethynylthien-2-yl-substituted porphyrins with its $\mathrm{Q}(0,0)$ and $\mathrm{Q}(1,0)$ bands showing the highest oscillator strengths. Accordingly, ZnT(TMSEtTh)P (2c) also shows the broadest fwhm of all the 5-trimethylethynylthien-2yl-substituted porphyrins.

Steady-State and Time-Resolved Fluorescence Emission. Tetrathien-2-yl Systems. The first striking feature of the mesotetrathien-2-yl fluorescence emission spectra is that the emission bands which arise from the $\mathrm{Q}(0,0) *$ and $\mathrm{Q}(0,1)^{*}$ excited states are almost completely unresolved due the large red shift of the higher energy $\mathrm{Q}(0,0)^{*}$ band (Figure 3(i)). The $\mathrm{Q}(0,1)^{*}$ band, for all thien-2-yl porphyrins, only shows a slight red shift when compared to ZnTPP (Table 1). This trend is evident in the Stokes shift for the $\mathrm{Q}(0,0) *$ emission band. The fluorescence quantum yields $\left(\Phi_{\mathrm{fl}}\right)$ and lifetimes $\left(\tau_{\mathrm{ff}}\right)$ for each of the meso-tetrathien2-yl porphyrins are reduced considerably relative to ZnTPP (Table 1). ZnTBrThP (2b), having four heavy bromine atoms, shows the lowest quantum yield $\left(\Phi_{\mathrm{fl}}=0.006\right)$ and the shortest fluorescence lifetime $\left({ }^{1} \tau=0.52 \mathrm{~ns}\right)$ for the thien-2-yl porphyrins studied here.

Mono-, Di-, Tri-, and Tetrathien-2-yl Systems. Fluorescence emission spectra for the mono-, di-, tri-, and tetra(5-trimethylsilylethynylthien-2-yl)porphyrins are shown in Figure 3(ii). The mono- and di(5-trimethylsilylethynylthien-2-yl)porphyrins show a $39 \%$ and $27 \%$ increase in $\Phi_{\mathrm{fl}}$, respectively, in comparison to ZnTPP, which can be attributed to an increased intensity of the $\mathrm{Q}(0,0)^{*}$ emission band. As the number of 5-trimethylsilylethynylthien-2-yl substituents on the macrocycle increases the intensity of both emission bands decreases with a concurrent red shift of their $\lambda_{\max }$. The higher energy $\mathrm{Q}(0,0)^{*}$ band shows a much stronger red shift and decrease in intensity ultimately resulting in an overlap of both bands which appear to have equal intensity for ZnT(TMSEtTh)P (2c), a trend that is again evident in the Stokes shift for the $\mathrm{Q}(0,0) *$ emission band (Table 1). For the mono-, di-, tri-, and tetra(5-trimethylsilylethynylthien2-yl)porphyrins $\Phi_{\mathrm{fl}}$ and $\tau_{\mathrm{fl}}$ both decrease linearly with increasing thien-2-yl substitution with a corresponding increase in $k_{\mathrm{nr}}$ (Table 1). A plot of "number of thienyl substituents" vs "quantum yield" and "fluorescence lifetime" illustrates this correlation (Figure 4). ${ }^{23}$ The reduced $\Phi_{\mathrm{fl}}$ for tetrathienylporphyrins has been previously attributed to the heavy atom effect due to the presence of four sulfur atoms on the periphery of the porphyrin ring. ${ }^{10 f}$ Distortion of the planar macrocycle and the reduced dihedral angle of the thienyl group at the porphyrin ring both serve to

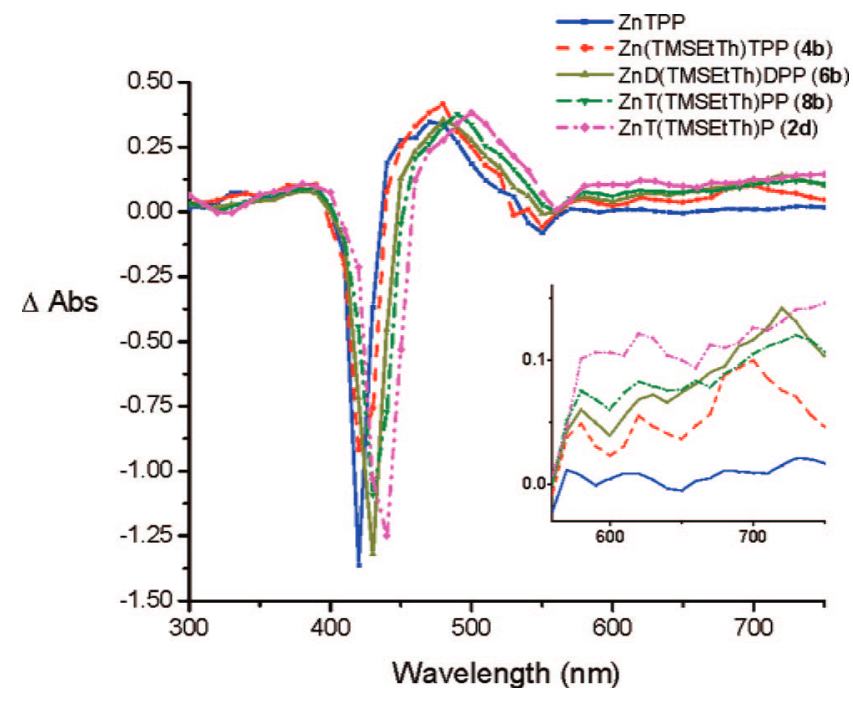

Figure 5. An overlay of the transient absorption difference spectra of ZnTPP, ZnTMSEtThTPP (4b), ZnD(TMSEtTh)DPP (6b), ZnT(TMSEtTh)PP (8b), and ZnT(TMSEtTh)P (2d) following laser excitation at $532 \mathrm{~nm}$ under $1 \mathrm{~atm}$ of argon. Each plot is recorded at a delay time of $2 \mu$ s after the laser pulse and all spectra have been recorded with an OD of 0.05 at $532 \mathrm{~nm}$.

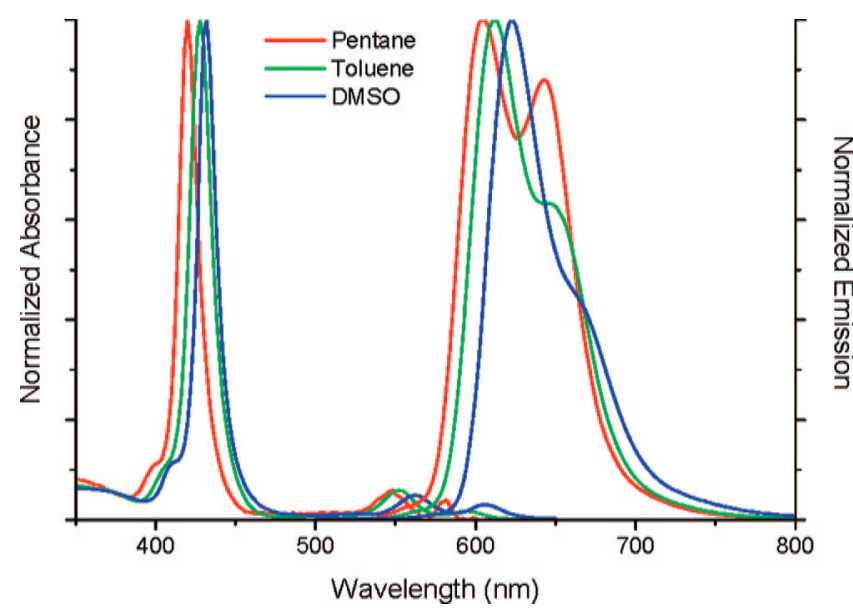

Figure 6. An overlay of the UV-vis absorption and fluorescence emission spectra of $\mathrm{Zn}(\mathrm{AldThEtTh}) \mathrm{TPP}$ (4d) recorded in pentane, toluene, and DMSO (all spectra have been normalized).

increase the conformational freedom of these systems with respect to ZnTPP, which may have electronic consequences manifested in decreased $\Phi_{\mathrm{fl}}$ and $\tau_{\mathrm{fl}}$ and increased $k_{\mathrm{nr}}$. It is possible that a shift of electron density onto the thienyl ring upon excitation results in decreased spin-orbit coupling and $k_{\text {isc }}$ for $\mathrm{Zn}$ (TMSEtTh)TPP (4b) relative to ZnTPP, i.e., one heavy sulfur atom on the periphery of the ring will have a decreased spin-orbit coupling in comparison to the central metal. However, spin-orbit coupling and $k_{\text {isc }}$ are increased as the number of thienyl units is increased thus becoming more efficient than for the central zinc atom of ZnTPP. This excited state charge transfer hypothesis is supported by the trend seen in the decreasing fluorescence lifetimes and quantum yields observed upon increasing the number of thienyl substituents and is also borne out in the transient absorption studies discussed below.

${ }^{3}(\Pi-\Pi *)$ Excited State Absorption and Decay. Tetrathien2-yl Systems. The excited state transient absorption difference spectrum of ZnTPP is characterized by a weak absorption from 300 to $390 \mathrm{~nm}$ in the UV region and from 435 to $538 \mathrm{~nm}$ in the visible with a $\lambda_{\max }$ at $470 \mathrm{~nm}$ (Figure S8, Supporting Informa- 


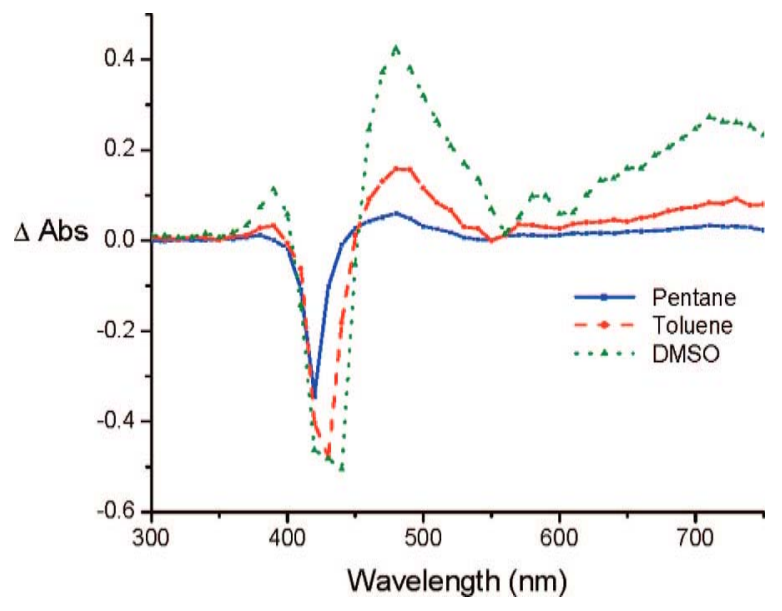

Figure 7. An overlay of the transient absorption difference spectra of Zn(AldThEtTh)TPP (4d) in pentane, toluene, and DMSO following $532 \mathrm{~nm}$ excitation under $1 \mathrm{~atm}$ of argon. Each plot is taken $2 \mu$ s after the laser pulse and all spectra have been recorded with an identical ground state optical density at $532 \mathrm{~nm}$.

tion). Saturation of the detector occurs between 400 and 435 $\mathrm{nm}$, which corresponds to the Soret band of the parent species. Isosbestic points are present at 400, 435, and $538 \mathrm{~nm}$. Only weak absorptions are observed at longer wavelengths for ZnTPP. The meso-tetrathien-2-ylporphyrins show a red-shifted transient absorption difference spectrum relative to ZnTPP with the $\lambda_{\max }$ occurring in the region 490-500 nm (Figure S9, Supporting Information). Also, there is a substantial increase in the lower energy absorption that stretches from ca. $580 \mathrm{~nm}$ right out to $750 \mathrm{~nm}$ (i.e., the detection limit of the instrument), and possibly into the near-IR region of the spectrum, perhaps due to charge transfer onto the peripheral thien-2-yl $\pi$-system. A similar phenomenon has been reported for an ethynylthiophone bridged bis-Ru(bpy) ${ }^{2+}$ system. $^{24}$ An increase in the intensity of this lowenergy charge transfer excited state absorption is observed with $\operatorname{ZnT}($ TMSEtTh)P (2c) > ZnTEtThP (2d) > ZnTThP (2a) > ZnTBrThP (2b) > ZnTTP.

Mono-, Di-, Tri-, and Tetrathien-2-yl Systems. The transient difference absorption spectra of the mono-, di-, tri-, and tetra(5trimethylsilylethynylthien-2-yl)porphyrins are red-shifted relative to ZnTPP with their $\lambda_{\max }$ occurring at $480,480,490$, and 500 $\mathrm{nm}$, respectively. The low-energy absorption at $>580 \mathrm{~nm}$ is present for each of these systems and becomes more pronounced on increasing thien-2-yl substitution further suggesting the possibility of it being a charge transfer band (Figure 5). Indeed this low-energy absorbance is most prominent for the 5-trimethylsilylethynylthien-2-yl- and 5-ethynylthien-2-yl-substituted porphyrins (Figure S10, Supporting Information). These characteristic excited state properties suggest a relatively strong increase in the electronic coupling of the porphyrin ring and the thien-2-yl $\pi$-network upon excitation. A decrease in the triplet lifetime is observed for the meso-tetrathien-2-ylporphyrins relative to ZnTPP and also on increasing 5-trimethylsilylethynylthien-2-yl substitution of the porphine ring (Table 1). The shortest lifetime, $7 \mu \mathrm{s}$, is again displayed by ZnTBrThP (2b).

Zn(AldThEtTh)TPP Solvatochroism. ZnTMSEtThTPP (4d) was successfully coupled at the terminal ethynyl moiety to 5-bromo-2-thiophenecarboxaldehyde via Sonogashira coupling giving the porphyrin zinc(II)-5-(5'-(5'-ethynylthiophene-2'carboxaldehyde)thien-2'-yl)-10,15,20-triphenylporphyrin, Zn(AldThEtTh)TPP (4d), in high yield. Sizable red shifts are observed in its UV-vis spectra for the Soret band as well as a concurrent increase in the fwhm on going from pentane $\left(\lambda_{\max }=420 \mathrm{~nm}\right.$, fwhm $\left.=850 \mathrm{~cm}^{-1}\right)$ to toluene $\left(\lambda_{\max }=428 \mathrm{~nm}, \mathrm{fwhm},=928\right.$ $\left.\mathrm{cm}^{-1}\right)$ and DMSO $\left(\lambda_{\max }=432 \mathrm{~nm}\right.$, fwhm $\left.=1018 \mathrm{~cm}^{-1}\right)$ as can be seen in Figure 6. Similarly, red shifts are observed in the Q-band region of the spectrum on going from pentane $\left(\lambda_{\mathrm{Q}(0,1)}\right.$ $\left.=548 \mathrm{~nm} \lambda_{\mathrm{Q}(0,0)}=582 \mathrm{~nm}\right)$ to toluene $\left(\lambda_{\mathrm{Q}(0,1)}=552 \mathrm{~nm} \lambda_{\mathrm{Q}(0,0)}\right.$ $=594 \mathrm{~nm})$ to DMSO $\left(\lambda_{\mathrm{Q}(0,1)}=562 \mathrm{~nm} \lambda_{\mathrm{Q}(0,0)}=606 \mathrm{~nm}\right)$. An increase in the ratio of absorbance of $\mathrm{Q}(0,0) / \mathrm{Q}(0,1)$ is also observed indicating a solvent dependency on the energy difference between the $\mathrm{a}_{1 \mathrm{u}} \rightarrow \mathrm{e}_{\mathrm{g}}$ and $\mathrm{a}_{2 \mathrm{u}} \rightarrow \mathrm{e}_{\mathrm{g}}$ transitions and increasing stabilization of a charge transfer state with increasing solvent polarity. The fluorescence spectra show similar solvatochromic behavior with a decreased quantum yield as the solvent polarity increases (Figure 6). The $\mathrm{Q}(0,0)^{*}$ emission band is red-shifted from $604 \mathrm{~nm}$ in pentane to $614 \mathrm{~nm}$ in toluene and to $623 \mathrm{~nm}$ in DMSO. The $\mathrm{Q}(0,1)^{*}$ emission band is also red-shifted on increasing solvent polarity; however, this shift is not as strong as that for the $\mathrm{Q}(0,0)^{*}$ emission band thus resulting in a slight convergence of the two peaks in toluene and DMSO. Such strong solvatochromic behavior, especially an increased Stokes shift, reflects a large change in dipole moment between the ground and excited states, i.e., $\mu_{\mathrm{g}}$ vs $\mu_{\mathrm{e}}$, according to the Lippert-Mataga equation, indicative of charge transfer character. ${ }^{25}$ Surprisingly the fluorescence lifetime is identical to that for ZnEtThTPP (4c) in toluene (1.92 ns). However, the triplet lifetime is reduced by more than $50 \%$ from $15 \mu$ s for ZnEtThTPP (4c) to $6 \mu$ s for Zn(AldThEtTh)TPP (4d) in toluene. Both the singlet and triplet lifetimes are slightly shorter in DMSO (1.20 ns and $5 \mu \mathrm{s}$, respectively). The transient absorption difference spectrum of Zn(AldThEtTh)TPP (4d) in toluene displays similar characteristics to that of ZnEtThTPP (4c); however, there is a substantial increase in the intensity of low-energy absorption, further validating the hypothesis that this

TABLE 2: Redox Potentials of the Thien-2'-ylporphyrins in Dichloromethane Reported vs. Fc/Fc ${ }^{+a}$

\begin{tabular}{|c|c|c|c|c|c|c|c|}
\hline \multirow[b]{2}{*}{ porphyrin } & \multicolumn{2}{|c|}{ oxidation (V) } & \multicolumn{5}{|c|}{ reduction $(\mathrm{V})$} \\
\hline & $1 \mathrm{st}$ & 2nd & $E_{\mathrm{pc}}{ }^{b}$ & $1 \mathrm{st}$ & $E_{\mathrm{pc}}^{b}$ & 2 nd & $E_{0-0}(\mathrm{eV})$ \\
\hline ZnTPP & 0.344 & 0.664 & -1.907 & -1.847 & -2.283 & -2.211 & 2.09 \\
\hline ZnTThP (2a) & 0.429 & 0.625 & -1.787 & -1.712 & -2.131 & -2.048 & 2.04 \\
\hline ZnTBrThP (2b) & 0.613 & 0.522 & -1.664 & & -1.939 & & 2.02 \\
\hline ZnTEtThP (2c) & 0.485 & 0.694 & -1.699 & & -2.184 & & 2.02 \\
\hline ZnT(TMSEtTh)P (2d) & 0.491 & 0.655 & -1.690 & -1.675 & -2.028 & & 2.01 \\
\hline Zn(TMSEtTh)TPP (4b) & 0.420 & 0.674 & -1.862 & & -2.041 & & 2.06 \\
\hline $\mathrm{ZnD}$ (TMSEtTh)DPP (6b) & 0.442 & 0.674 & -1.743 & & -2.056 & & 2.04 \\
\hline ZnT(TMSEtTh)PP (8b) & 0.443 & 0.664 & -1.725 & & -2.017 & & 2.02 \\
\hline Zn(ThEtThAld)TPP (8d) & 0.421 & 0.681 & -1.809 & -1.823 & -2.198 & & 2.04 \\
\hline
\end{tabular}

${ }^{a}$ All cyclic voltammograms were measured at a scan rate of $100 \mathrm{mV} \mathrm{s}^{-1}$, using a glassy carbon working electrode. ${ }^{b}$ Due to irreversibility of porphyrin reduction all $E_{\mathrm{pc}}$ data are included. 
is an excited state charge transfer transition (Figure 7). This transition gains in oscillator strength on increasing the solvent polarity as seen in Figure 7. The appearance of this low-energy band and its enhanced absorption in a polar medium suggests that there is enhanced electronic communication between the porphyrin $\pi$-system and the meso-thien-2-yl moiety on going from the ground state to the excited state of $\mathrm{Zn}$ (AldThEtTh)TPP (4d).

Cyclic Voltammetry. Tetrathien-2-yl Systems. Substitution with a thien-2-yl moiety at the meso-position of the porphyrin ring has a significant effect on its redox properties. The two $E_{1 / 2}$ values observed at positive potential correspond to the first and second reversible oxidations of the porphyrin ring, which result in the formation of the porphyrin cation radical and porphyrin monocation, respectively (Table 2 ). There are generally two redox couples also present at negative potential corresponding to the formation of the porphyrin anion radical and monoanion species. All of the meso-tetrathien-2-ylporphyrins show an anodic shift of their first oxidation relative to ZnTPP indicating a stabilization of the $\mathrm{a}_{2 \mathrm{u}}$ (HOMO) orbital of the porphyrin ring in these systems. ZnTBrThP (2b) displays the largest effect with a $E_{1 / 2}$ value $269 \mathrm{mV}$ greater than the first oxidation of ZnTPP. The LUMO orbitals are also stabilized upon meso-thien-2-yl substitution relative to ZnTPP. ZnTBrThP (2b) again shows the largest effect with a decrease in the potential of the first cathodic reduction peak of over $240 \mathrm{mV}$. ZnTThP (2a), ZnT(TMSEtTh)P (2c), and ZnTEtThP (2d) each show a decrease in the first cathodic reduction peak by 85,147 , and $141 \mathrm{mV}$, respectively.

Mono-, Di-, Tri-, and Tetrathien-2-yl Systems. Enhanced stabilization of both the HOMO and LUMO orbitals is observed on increasing thien-2-yl substitution, but is more pronounced for the LUMO orbitals. The cyclic voltammogram of $\mathrm{Zn}$ (AldThEtTh)TPP (4d) is similar to that obtained for ZnEtThTPP (4c) in that it displays two reversible porphyrin-based oxidations and two reduction processes (Figure S15). Both the HOMO and LUMO orbitals are stabilized by 77 and $98 \mathrm{mV}$, respectively, with respect to ZnTPP, which results in a decrease in the band gap of $21 \mathrm{mV}$ and an excited state oxidation potential of -1.809 V. The decrease in reduction potential, i.e., LUMO energy, observed on increasing thien-2-yl substitution at the porphyrin ring appears to be the dominant factor that determines the reduced band gap and excited state oxidation potential for these systems (Table 2). An overall reduction in porphyrin band gap $\left(E_{0-0}\right)$ is observed on increasing 5-trimethylsilylethynylthien2-yl substitution with ZnT(TMSEtTh)P (2d) $<$ ZnT(TMSEtTh)PP (8b) < ZnD(TMSEtTh)DPP $(\mathbf{6 b})<$ Zn(TMSEtTh)TPP (4b) < ZnTPP (Table 2).

\section{Conclusions}

A series of $\mathrm{Zn}(\mathrm{II})-$ meso-tetrathien-2-ylporphyrins and mono-, di-, tri-, and tetrathien-2-yl porphyrin systems have been prepared. UV-vis absorption, steady-state/time-resolved fluorescence, and electrochemical data all point toward substantial electronic communication between the central $\mathrm{Zn}$ (II)-porphyrin macrocyle and the meso-thien-2-yl substituents. In particular, excited state difference absorption spectra, viz. laser flash photolysis studies, show evidence of a porphyrin-to-thieny-2yl charge transfer band. This excited state charge transfer process has been used to explain the decreased quantum yields and fluorescence lifetimes of meso-substituted thien-2-yl porphyrin systems relative to ZnTPP. By varying the number of 5-trimethylsilylethynylthien-2-yl groups on the traditional $\mathrm{N}_{4}$-core porphyrin ring, from one through to four, the photophysical and electrochemical properties of the macrocycle were modulated. The $\pi$-extended $\mathrm{AB}_{3}$-type porphyrin system $\mathrm{Zn}(\mathrm{AldThEtTh}) \mathrm{TPP}$ (4d) shows enhanced excited state charge transfer character from the porphyrin macrocycle to the peripheral ( 5 "-ethynylthiophene-2'-carboxaldehyde)thien-2'-yl moiety also indicating substantial electronic communication between the two ring systems making such systems attractive toward the design of artificial photosynthetic devices.

Acknowledgment. The authors gratefully acknowledge the support of Enterprise Ireland and Dublin Co. Council (J.R.) for funding this research.

Supporting Information Available: Synthesis of all porphyrins here studied, ${ }^{1} \mathrm{H}$ NMR spectra, time correlated single photon counting spectra, transient absorption difference spectra, excited state decay profiles, and cyclic voltammetry of $\mathrm{Zn}$ (AldThEtTh)TPP (4d). This material is available free of charge via the Internet at http://pubs.acs.org.

\section{References and Notes}

(1) Simonneaux, G.; Le Maux, P. Coord. Chem. Rev. 2002, 228, 43 (2) Lang, K.; Mosinger, J.; Wagnerová, D. M. Coord. Chem. Rev. 2004, 248,321

(3) Calvete, M.; Yang, G. Y.; Hanack, M. Synth. Met. 2003, 141, 231.

(4) (a) The Porphyrin Handbook; Kadish, K. M., Smith,K. M., Guilard, R., Eds.; Academic Press: Boston, MA, 2000; Vol. 8. (b) The Porphyrin Handbook; Kadish, K. M., Smith,K. M., Guilard, R., Eds.; Academic Press: Boston, MA, 2003; Vol. 18. (c) Galoppini, E.; Rochford, J.; Chen, H.; Saraf, G.; Lu, Y.; Hagfeldt, A.; Boschloo, G. J. Phys. Chem. B 2006, 110, 16159 (d) Rochford, J.; Chu, D.; Hagfeldt, A.; Galoppini, E. J. Am. Chem. Soc 2007, 129, 4655. (e) Rochford, J.; Galoppini, E. Langmuir 2008, 24, 5366.

(5) (a) Torréns, M. A.; Straub, D. K.; Epstein, L. M. J. Am. Chem. Soc. 1972, 94, 4160. (b) Ono, N.; Miyagawa, H.; Ueta, T.; Ogawa, T.; Tani, H. J. Chem. Soc., Perkin Trans. 1 1998, 1595. (c) Harada, A. Shiotsuki, K.; Fukushima, H.; Yamaguchi, H.; Kamachi, M. Inorg. Chem. 1995, 34, 1070. (d) Li, G.; Doblhofer, K.; Fuhrhop, J.-H. Angew. Chem., Int. Ed. 2002, 41, 2730.

(6) (a) Segawa, H.; Wu, F.-P.; Nakayama, N.; Maruyama, H.; Sagisaka, S.; Higuchi, N.; Fujitsuka, M.; Shimidzu, T. Synth. Met. 1995, 71, 2151 (b) Shimidzu, T.; Segawa, H.; Wu, F.; Nakayama, N. J. Photochem. Photobiol. A: Chem. 1995, 926, 121. (c) Maruyama, H.; Segawa, H.; Sotoda, S.; Sato, T.; Kosai, N.; Sagisaka, S.; Schimidzu, T.; Tanaka, K. Synth. Met. 1998, 96, 141. (d) Yamamoto, T.; Fukushima, N.; Nakjima, H.; Maruyama, T.; Yamaguchi, I. Macromolecules 2000, 33, 5988. (e) Yamamoto, T. Nakjima, H.; Hayashida, N.; Shiraishi, K.; Kokubu, H. Polym. Adv. Technol. 2000, 11, 658. (f) Yuasa, M.; Oyaizu, K.; Yamaguchi, A.; Ishikawa, M.; Eguchi, K.; Kobayashi, T.; Toyoda, Y.; Tsutsui, S. Polym. Adv. Technol. 2005, 16, 616. (g) Oyaizu, K.; Ishikawa, M.; Hoshino, M.; Imai, T.; Yuasa, M. J. Polym. Sci., Part A: Polym. Chem. 2006, 44, 5403. (h) Paul-Roth C. O.; Letessier, J.; Juillard, S.; Simonneaux, G.; Roisnel, T.; RaultBerthelot, J. J. Mol. Struct. 2008, 872, 105.

(7) (a) Albert, I. D. L.; Marks, T. J.; Ratner, M. A. Chem. Mater. 1998, 10, 753. (b) Ono, N.; Ito, S.; Wu, C. H.; Chen, C. H.; Wen, T. C. Chem. Phys. 2000, 262, 467. (c) Osuka, A.; Fujikane, D.; Shinmori, H.; Kobatake, S.; Irie, M. J. Org. Chem. 2001, 66, 3913. (d) Friedlein, R.; Crispin, X.; Osikowicz, W.; Braun, S.; de Jong, M. P.; Simpson, C. D.; Watson, M. D. von Kieseritzky, F.; Samorí, P.; Jönsson, S. K. M.; Fahlman, M.; Jäckel, F.; Rabe, J. P.; Hellberg, J.; Müllen, K.; Salaneck, W. R. Synth. Met. 2004, 147, 79. (e) Friedlein, R.; Kieseritzky, F.; Braun, S.; Linde, C.; Osikowicz, W.; Hellberg, J.; Salaneck, W. R. Chem. Commun. 2005, 1974. (f) Zhang, T.-G.; Zhao, Y.; Assellberghs, I.; Persoons, A.; Clays, K.; Therien, M. J. Am. Chem. Soc. 2005, 127, 9710. (g) Ray, P. R.; Leszczynski, J. Chem. Phys. Lett. 2006, 419, 578. Takahashi, H.; Kanehara, M.; Teranishi, T. J. Photopolym. Sci. Technol. 2007, 20, 133. (h) Rochford, J.; Botchway, S.; Rooney, A. D.; Pryce, M. T. Inorg. Chem. 2007, 46, 7247.

(8) (a) Nagai, K.; Iyoda, T.; Fujishima, A.; Hashimoto, K. Synth. Met. 1997, 85, 1701. (b) Keleman, M.; Wachter, C.; Winter, H.; Dormann, E.; Gompper, R.; Hermann, D. Mol. Phys. 1997, 90, 407.

(9) (a) Wurthner, F.; Vollmer, M. S.; Effenberger, F.; Emele, P.; Meyer, D. U.; Port, H.; Wolf, H. C. J. Am. Chem. Soc. 1995, 117, 8090. (b) Vollmer, M. S.; Wurthner, F.; Effenberger, F.; Emele, P.; Meyer, D. U.; Stumpfig, T.; Port, H.; Wolf, H. C. Chem. Eur. J. 1998, 4, 260. (c) Vollmer, M. S.; Effenberger, F.; Stumpfig, T.; Hartschuh, A.; Port, H.; Wolf, H. C. J. Org Chem. 1998, 63, 5080. (d) Janvier, P.; Lequestel, J.-Y.; Illien, B.; Suresh, S.; Blart, E.; Quintard, J.-P.; Odobel, F. Int. J. Quantum Chem. 2001, 84, 259. (e) Ikemoto, J.; Takimiya, K.; Aso, Y.; Otsubo, T.; Fujitsuka, M.; Ito, 
O. Org. Lett. 2002, 4, 309. (f) Odobel, F.; Suresh, S.; Blart, E.; Nicolas, Y.; Quintard, J.-P.; Janvier, P.; Le Questel, J.-Y.; Illien, B.; Rondeau, D. Richomme, P.; Häupl, T.; Wallin, S.; Hammarström, L. Chem. Eur. J. 2002, 8, 3027. (g) Okada, S.; Segawa, H. J. Am. Chem. Soc. 2003, 125, 2792. (h) Nakamura, T.; Fujitsuka, M.; Araki, Y.; Ito, O.; Ikemoto, J.; Takimiya, K. Aso, Y.; Otsubo, T. J. Phys. Chem. B 2004, 108, 10700. (i) Sun, M.; Song, P.; Chen, Y.; Ma, F. Chem. Phys. Lett. 2005, 416, 94. (j) Oike, T.; Kurata, T.; Takimiya, K.; Otsubo, T.; Aso, Y.; Zhang, H.; Araki, Y.; Ito, O. J. Am. Chem. Soc. 2005, 127, 15372. (k) Nakamura, T.; Ikemoto, J.; Fujitsuka, M.; Araki, Y.; Ito, O.; Takimiya, K.; Aso, Y.; Otsubo, T. J. Phys. Chem. $B$ 2005, 109, 14365. (1) Krebs, F. C.; Spanggaard, H. Sol. Energy Mater. Sol. Cells 2005, 88, 363. (m) Collis, G. E.; Campbell, W. M.; Officer, D. L. Burrell, A. K. Org. Biomol. Chem. 2005, 3, 2075. (n) Takechi, K.; Shiga, T.; Motohiro, T.; Akiyama, T.; Yamada, S.; Nakayama, H.; Kohama, K. Sol. Energy. Mater. Sol. Cells 2006, 90, 1322. (o) Eu, S.; Hayashi, S.; Umeyama, T.; Oguru, A.; Kawasaki, M.; Kadota, N.; Matano, Y.; Imahori, H. J. Phys. Chem C. 2007, 111, 3528.

(10) (a) Bhyrappa, P.; Bhavana, P. Chem. Phys. Lett. 2001, 349, 399 (b) Gupta, I.; Hung, C.-H.; Ravikanth, M. Eur. J. Org. Chem. 2003, 4392. (c) Sun, X.; Zhang, J.; He, B. J. Photochem. Photobiol. A: Chem. 2005, 172, 283. (d) Gupta, I.; Ravikanth, M. J. Photochem. Photobiol. A: Chem. 2006, 177, 156. (e) Bhyrappa, P.; Sankar, M.; Varghese, B.; Bhavana, P. J. Chem. Sci. 2006, 118, 393. (f) Brückner, C.; Foss, P. C. D.; O'Sullivan, J.; Pelto, R.; Zeller, M.; Birge, R. R.; Crundwell, G. Phys. Chem. Chem. Phys. 2006, 8, 2402.

(11) Pineiro, M.; Carvalho, A. L.; Pereira, M. M.; Gonsalves, A. M. d'A. R.; Arnaut, L. G.; Formosinho, S. J. Chem. Eur. J. 1998, 4, 2299.

(12) (a) Aspley, C. J.; Lindsay Smith, J. R.; Perutz, R. N.; Pursche, D. J. Chem. Soc., Dalton Trans. 2002, 170. (b) Prodi, A.; Indelli, M. T, Kleverlaan, C. J.; Scandola, F.; Alessio, E.; Gianferrara, T.; Marzilli, L. G. Chem. Eur. J. 1999, 5, 2668.

(13) Browne, W. R.; Coates, C. G.; Brady, C.; Matousek, P.; Towrie, M.; Botchway, S. W.; Parker, A. W.; Vos, J. G.; McGarvey, J. G. J. Am Chem. Soc. 2003, 125, 1706.

(14) Lindsey, J. S.; Schreiman, I. C.; Hsu, H. C.; Kearney, P.; Marguerettaz, A. M. J. Org. Chem. 1987, 52, 827.
(15) Lindsey J. S. In The Porphyrin Handbook; Kadish, K. M., Smith, K. M., Guilard, R., Eds.; Academic Press: Boston, MA, 2000; Chapter 2 , Vol. 1.

(16) All data reported here for the di(5-trimethylsilylethynylthien-2yl)porphyins are a mixture of the cis and trans isomer as they could not be separated at any stage of the synthesis. ${ }^{1} \mathrm{H}$ NMR data are included in the Supporting Information and the ratio of cis:trans could not be ascertained due to the similarity of both spectra.

(17) Due to the low energy of rotation of the thienyl rings at the meso position of the porphyrin ring each of the tetrathienylporphyrins studied here can be considered to be of pseudo- $S_{4}$ symmetry.

(18) Bonar-Law J. Org. Chem. 1996, 61, 3623.

(19) Lindsey, J. S.; Prathapan, S.; Johnson, T. E.; Wagner, R. W. UVvis spectra of analogous tetraaryl free base porphyrins show little difference from $\mathrm{H}_{2}$ TPP. Tetrahedron 1994, 50, 8941. (b) Li, F.; Gentemann, S.; Kalsbeck, W. A.; Seth, J.; Lindsey, J. S.; Holten, D.; Bocian, D. F. J. Mater. Chem. 1997, 7, 1245 .

(20) (a) Harriman, A.; Davila, J. Tetrahedron 1989, 45, 4737. (b) Fonda, H. N.; Gilbert, J. V.; Cormier, R. A.; Sprague, J. R.; Kamioka, K.; Connoly, J. S. J. Phys. Chem. 1993, 97, 7024.

(21) Spellane, P. J.; Gouterman, M.; Antipas, A.; Kim, S.; Liu, Y. C. Inorg. Chem. 1980, 19, 386.

(22) Gupta, I.; Hung, C.-H.; Ravikanth, M. Eur. J. Org. Chem. 2003 4392.

(23) The slope of "quantum yield" vs. "number of thien-2-yl substitutents" appears linear apart from the mono-thien-2-yl data point. This quantum yield is reduced more than anticipated due to increasing overlap of the $\mathrm{Q}(0,0)$ * fluorescence band with the $\mathrm{Q}(0,0)$ absorption band, i.e., a reduced Stokes shift.

(24) Barbieri, A.; Ventura, B.; Flamigni, L.; Barigelletti, F.; Fuhrmann, G.; Bauerle, P.; Goeb, S.; Ziessel, R. Inorg. Chem. 2005, 44, 8033.

(25) (a) Laurence, C.; Nicolet, P.; Dalati, M. T.; Abboud, J.-L. M.; Notario, R. J. Phys. Chem. 1994, 98, 5807. (b) Yamaguchi, Y.; Shimoi, Y.; Ochi, T.; Wakamiya, T.; Masubara, Y.; Yoshida, Z. J. Phys. Chem. A 2008, 112, 5074.

JP805809P 